\title{
BMJ Open Quality of medicines in Canada: a retrospective review of risk communication documents (2005-2013)
}

\author{
Tariq Almuzaini, Helen Sammons, Imti Choonara
}

To cite: Almuzaini T, Sammons H, Choonara I. Quality of medicines in Canada: a retrospective review of risk communication documents (2005-2013). BMJ Open 2014;4:e006088. doi:10.1136/bmjopen-2014006088

- Prepublication history and additional material is available. To view please visit the journal (http://dx.doi.org/ 10.1136/bmjopen-2014006088).

Received 10 July 2014 Revised 6 October 2014 Accepted 7 October 2014

CrossMark

Academic Division of Child Health, University of Nottingham, Derbyshire Children's Hospital, Derby, UK

\section{Correspondence to}

Tariq Almuzaini; mzxta@exmail.nottingham.ac. uk

\section{ABSTRACT}

Objective: To explore the quality and safety of medicines in Canada.

Design: A retrospective review of drug recalls and risk communication documents conveying issues relating to defective (ie, substandard and falsified) medicines.

Setting: The Health Canada website search for drug recalls and risk communication documents issued between 2005 and 2013.

Eligibility criteria: Drug recalls and risk communication documents related to quality defect in medicinal products.

Main outcome measure: Relevant data about defective medicines reported in drug recalls and risk communication documents, including description of the defect, type of formulation, year of the recall and category of the recall or the document.

Results: There were 653 defective medicines of which 649 were substandard. The number of defective medicines reported by Health Canada increased from 42 in 2005 to 143 in 2013. The two most frequently reported types of defects were stability (205 incidents) and contamination issues (139 incidents). Some of these defects were found to be more prominent and repetitive over other types within some manufacturers. Tablet formulation (251 incidents) was the formulation most frequently compromised. No significant differences were observed between the manufacturers and distributors in the number of substandard medicines reported under each defect type. There were only four falsified medicines reported over the 9-year period.

Conclusions: Substandard medicines are a problem in Canada and have resulted in an increasing number of recalled medicines. Most of the failures were related to stability issues, raising the need to investigate the root causes and for stringent preventative measures to be implemented by manufacturers.

\section{INTRODUCTION}

Defective medicines are a major public health problem. ${ }^{1-4}$ Different surveys in lower income countries and lower middle income countries have found that defective medicines are readily available. ${ }^{35}$

Defective medicine is a term used to describe any drug with a quality defect,
Strengths and limitations of this study

- It is the first review to assess the problem of defective medicines in Canada.

- It quantifies and analyses drug recalls in Canada over a 9-year period.

- Clinical significance of the problem is undetermined, owing to the lack of data from Health Canada regarding adverse events associated with the use of defective medicines.

whether the error was due to deliberate falsification or unintentional error during manufacturing. ${ }^{6}{ }^{7}$ It is a large category that comprises two main types of compromised drugs, substandard and falsified medicines. A substandard medicine is a medicine that does not meet the regulator standards due to an unintentional or negligent error. ${ }^{8}$ A falsified medicine, however, is one where deliberate and criminal intent is involved. ${ }^{8}$

In high-income countries (HIC), there have been no studies with good methodological quality examining the overall prevalence of substandard or falsified medicines. ${ }^{3}$ The surveillance system in HIC in Europe and North America, however, is a wellestablished system that has identified and withdrawn several medicines from the market with serious safety concerns. ${ }^{9} 10$ These surveillance systems have reported numerous incidents of substandard and falsified medicines, and highlighted the problem of such drugs in these countries. Examples of these are the falsified cancer drug, avastin, and substandard spinal steroid injections reported in the USA. ${ }^{11} 12$ In our previous study on the UK, we studied the problem of defective medicines in the UK by reviewing the drug alerts issued by the drug regulator over an 11-year period. The study showed that substandard medicines are a problem that appears to be increasing. ${ }^{7}$ We wished to explore another HIC and chose Canada, as the problem of defective medicines has never been explored in this setting 
and because of the level of data available in the public domain.

In Canada, health products are regulated by Health Canada, which is the federal department responsible for the monitoring and regulating of medicines. ${ }^{13}$ It issues a number of risk communication documents to the public and healthcare professionals. These involve identification of the possible risk, assessment of its severity and clarification of the nature of the problem. This communication is also initiated to disseminate information regarding new safety issues of medicines or existing health risks to allow healthcare professionals and their patients to make wellinformed decisions about their health. ${ }^{14}$

The aim of this study was to explore the quality and safety of medicines in Canada by analysing the risk communication documents conveying issues relating to defective medicines.

\section{METHODS}

Health Canada uses 13 risk communication documents, which can be issued for the public, healthcare professionals and hospitals. ${ }^{14}$ A preliminary search for these risk communication documents found that only five documents can be used by Health Canada to convey any defective health product issue in the Canadian official supply chain. These can be described as follows:

- Public Warning $(P W)$ : issued by Health Canada if the use of the drug can cause a severe adverse health consequence that may lead to death.

- Public Advisory (PA): issued by Health Canada if exposure to or the use of the drug can cause adverse health consequences, but is not life threatening or serious.

- Healthcare Professional Communication-Notice to Hospitals (HPC-NtoH): to inform the healthcare professional about time-sensitive issues concerning safety and/or efficacy of medicinal products. It is intended for hospital use only.

- Healthcare Professional Communication-Dear Health Care Professional Letter (HPC-DHCPL): to inform the healthcare professional about issues regarding safety and/or efficacy of medicinal products.

- Health Product Recall (with type I, II or III): these can be classified according to the urgency of the recall as follows:

- Health Product Recall type I: issued if the health product can cause severe adverse health consequence that may lead to death.

- Health Product Recall type II: issued if the exposure to or the use of the health product can cause adverse health consequences but is not life threatening or serious.

- Health Product Recall type III: the exposure to or use of the health product is not likely to cause any harm but the recall is initiated for other reasons such as minor deviation from specifications.

Both PW and Health Product Recall type I are considered by Health Canada to be urgent communications, as they are issued for a medicine which may pose a serious health risk. PA, HPC-NtoH, HPC-DHCPL and type II and III Health Product Recalls are semiurgent communications where the risk associated with the use of a medicine is not serious. ${ }^{14}$

A search for risk communication documents conveying issues relating to defective medicines (ie, substandard and falsified medicines) was carried out. This was performed through the official Health Canada's website and using the search engine allocated for advisories, warnings and recalls of health products (http://www. hc-sc.gc.ca/dhp-mps/medeff/advisories-avis/index-eng.

php). Health Canada started posting Health Product Recalls on its website in 2005 . These recalls are the main tool that Health Canada uses to convey quality issues with medicines. Before that, there were only two types of risk communication documents (PA and HPC-DHCPL) available on Health Canada's website. We wanted to examine the same documents throughout the years. Therefore, the search was started from 2005, and all risk communication documents issued between 1 January 2005 and 31 December 2013 were included. All risk communication documents (PW, PA, HPC-DHCPL, HPC-NtoH and Health Product Recalls) were reviewed and the relevant information was then extracted.

All relevant information regarding defective health products was compiled and exclusion criteria were as follows: veterinary medicines; medicines lacking efficacy or acquiring general safety issues; herbal and probiotic products; dietary and cosmetic products; and other natural heath product recalled for regulatory reason (ie, those do not have a valid marketing authorisation). The following data were extracted from the risk communication documents: name, strength and dosage form; year of the document; nature of the defect; type of drug recall (in the case of Health Product Recalls); and action to be taken by healthcare professionals or the public regarding the defective medicine. In the case of Health Product Recalls and PW, the action is to remove the defective medicine from the dispensary shelves and contact the manufacturer for return. Whereas, with other risk communication documents where there is no recall required, healthcare professionals and the public are given advice on how to deal with defective medicines and to alert the public to be aware of expected risks. Two types of drugs can be distinguished from risk communication documents: substandard drugs and falsified drugs. The decision on which incident was falsified or substandard is that published by Health Canada.

The type of defects were then classified using the same classification as used in our previous study. ${ }^{7}$ The quality defects were classified as contamination, minor or major packaging defect, delivery (eg, leaking bags) defect, stability failure, potency issues, active ingredient defect and other issues (such as other deviations concerning noncompliance with good manufacturing practice at manufacturing site). 
The WHO Anatomical Therapeutic Chemical (ATC) Classification System was used to classify defective medicines. ${ }^{15}$ The first level of this classification categorises medicines according to the organ or system in which they act and the second level classifies medicines according to their main therapeutic group. This was performed to highlight the most frequent therapeutic classes affected by these recalls.

\section{Method of analysis}

Minitab (V.16) software was used to store and analyse the data. Descriptive statistics were used to summarise the results. Marketing authorisation holders of recalled medicines were either licensed manufacturers or distributors. A comparison between the manufacturers and distributors in the number of substandard medicines reported under each type of quality defect was carried out using Fisher's exact test. A significant difference was defined at a $\mathrm{p}$ value $<0.05$. The comparison was conducted to investigate if there are certain types of quality defects (eg, stability or packaging issues) that were more likely to be reported with distributors, as this may indicate non-compliance with Good Distribution Practices.

\section{RESULTS}

A total of 653 defective medicines were identified in the Canadian supply chain (figure 1). Among these defective medicines, 649 were found to be substandard medicines, and only four were found to be falsified medicines in the 9 years studied. The rate of reporting defective medicines has increased each year over the past 6 years (figure 2).

\section{Substandard medicines}

Substandard medicines represent the bulk of defective medicines $(\mathrm{n}=649,99 \%)$ reported by Health Canada.
The two most frequent types of defects reported were stability $(n=205,32 \%)$ and contamination $(n=139,21 \%)$ issues (table 1). It is clear that substandard medicines with stability defects represent the largest group. The majority of these formulations were found to have degraded 1 year after their release into the market, resulting in low concentrations of active ingredients, impurities, dissolution and disintegration failures. Tablets were the formulation most frequently reported to be substandard (see online supplementary table $\mathrm{S} 1$ ).

Among the 649 substandard medicines, 89 (14\%) were subjected to urgent communications and therefore required urgent recalls. These medicines were reported using the Health Product Recall type $1(n=87)$ and the PW $(n=2)$. More than half of these medicines $(n=46$, $52 \%$ ) were parenteral formulations (tables 2 and 3 ). Of the 89 medicines that were recalled, 34 were contaminated. The majority of these were parenteral formulations that were recalled due to the presence of particulate matters, the presence of microbes or a lack of sterility assurance during their manufacture (table 2 ). The remaining substandard medicines $(n=55)$ were urgently recalled due to other types of defects (table 3 ), mainly packaging defects or delivery issues (such as cracks in the vials or leaks in the bags, as well as faults in the unit used to deliver the medicines). Packaging defects were one of the major clinical issues reported, and these included incorrect labelling (ie, wrong drug name, strength or expiry date) and packaging that lacked important information regarding safety or the use of medicines in the patient information leaflets. In some cases, the labelling was correct, but the wrong medicines were filled, resulting in major and urgent recalls of affected batches (table 3 ).

Other substandard medicines $(\mathrm{n}=560,86 \%)$ were subjected to semiurgent recalls $(n=536)$ or caution in use $(n=24)$. These were reported via the Health Product

Figure 1 Flow diagram of search and resulting incidents.

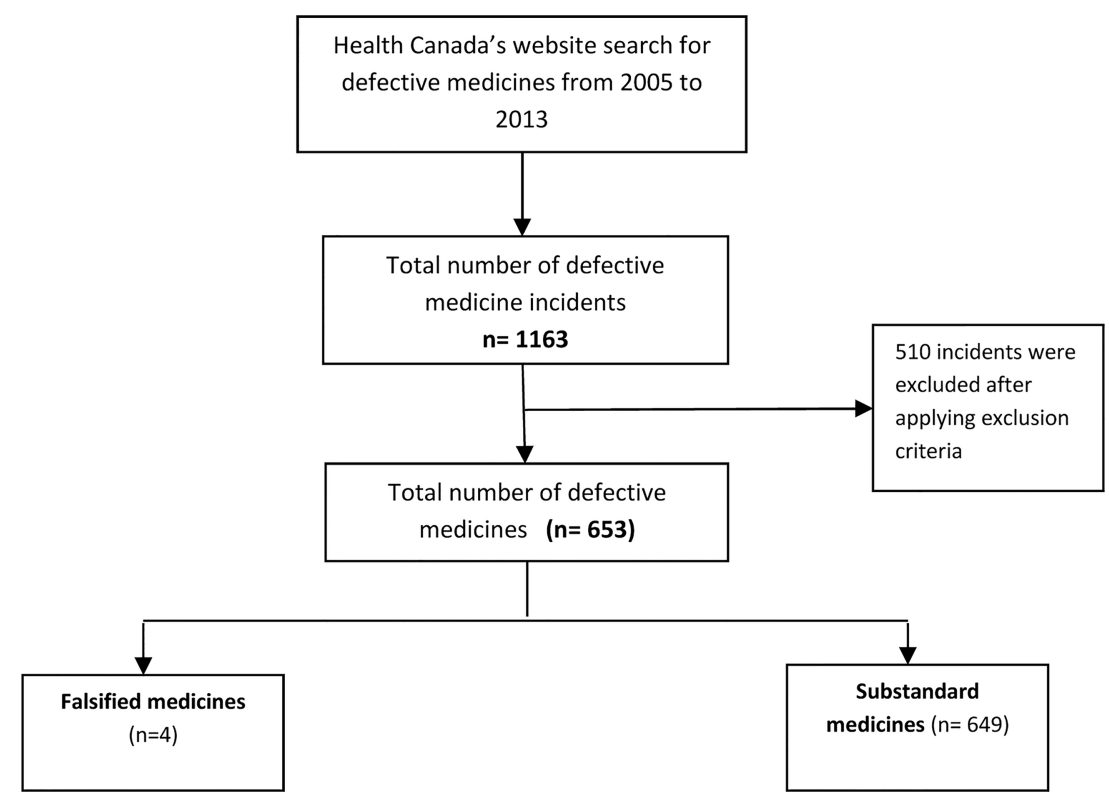


Figure 2 Number of incidents of defective medicines reported by Health Canada.

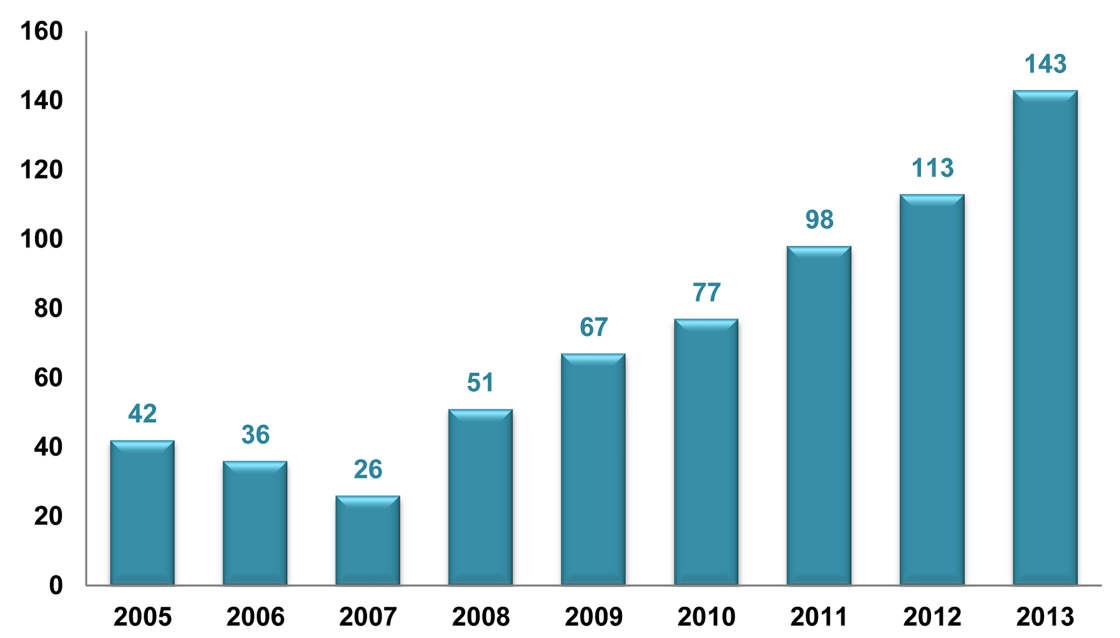

$\square$ Number of incidents of defective medicines reported by Health Canada
Recall type II ( $\mathrm{n}=288$ medicines, 44\%) and III $(\mathrm{n}=\mathbf{2 4 5}$, $38 \%)$, PA $(\mathrm{n}=8,1 \%)$, HPC-NtoH $(\mathrm{n}=9,1 \%)$ and HPC-DHCPL $(\mathrm{n}=7,1 \%)$. Three medicines were recalled, but the corresponding type of Heath Product Recall was not given by Health Canada. The majority of these drugs had stability, contamination and packaging defects (see online supplementary table S2).

Drugs that act on the nervous system $(n=141,22 \%)$, alimentary tract and metabolism $(\mathrm{n}=90,14 \%)$, and cardiovascular system $(n=83,13 \%)$ were the subgroups that most frequently contained substandard medicines. When the second level of this classification (ie, therapeutic classification) was used, the top three groups reported to be substandard were analgesics $(n=65$, $10 \%)$, antihypertensives $(\mathrm{n}=50,8 \%)$ and antibacterials $(\mathrm{n}=38,6 \%$; see online supplementary table $\mathrm{S} 3)$.

\section{Substandard medicines categorised by manufacturers}

The review identified 122 licensed manufacturers and 26 licensed distributors. Manufacturers held the

\section{Table 1 Substandard medicines}

\begin{tabular}{|c|c|c|c|c|}
\hline Defect type & $\begin{array}{l}\text { Number of } \\
\text { medicines }\end{array}$ & $\begin{array}{l}\text { Per } \\
\text { cent }\end{array}$ & Defect details & $\begin{array}{l}\text { Number } \\
\text { of } \\
\text { medicines }\end{array}$ \\
\hline \multirow[t]{4}{*}{ Stability defects } & 205 & 32 & Concern about stability of active ingredients & 63 \\
\hline & & & Levels of impurities in excess of specification at different time points & 50 \\
\hline & & & Dissolution, disintegration and drug release failure & 45 \\
\hline & & & Others & 47 \\
\hline \multirow[t]{3}{*}{ Contamination } & 139 & 21 & Impurities & 82 \\
\hline & & & Lack of sterility assurance & 35 \\
\hline & & & Microbial contamination & 22 \\
\hline \multirow[t]{2}{*}{$\begin{array}{l}\text { Minor packaging } \\
\text { defects }\end{array}$} & 71 & 11 & $\begin{array}{l}\text { Fault involving the external packaging or minor printing errors that } \\
\text { do not involve name or strength of a medicine }\end{array}$ & 60 \\
\hline & & & $\begin{array}{l}\text { Missing or incorrect product registration number, batch number, } \\
\text { manufacturer's name or expiry date }\end{array}$ & 11 \\
\hline \multirow[t]{2}{*}{$\begin{array}{l}\text { Major packaging } \\
\text { defects }\end{array}$} & 65 & 10 & $\begin{array}{l}\text { Missing or incorrect name, strength, or active ingredient of a } \\
\text { medicine on carton or box }\end{array}$ & 35 \\
\hline & & & $\begin{array}{l}\text { Packing a medicine in the wrong carton or present of a foreign } \\
\text { tablet or capsule in the bottle or blister }\end{array}$ & 30 \\
\hline \multirow{3}{*}{$\begin{array}{l}\text { Defects in active } \\
\text { ingredient }\end{array}$} & 62 & 10 & Excessive amount of active ingredients & 26 \\
\hline & & & Inadequate amount of active ingredient & 20 \\
\hline & & & Active ingredient is out of specification & 16 \\
\hline \multirow[t]{3}{*}{ Delivery defects } & 35 & 5 & Fault with a device & 22 \\
\hline & & & Leakage or loose/ tight seal, cracks in a vial or broken tablets & 9 \\
\hline & & & Others & 4 \\
\hline \multirow[t]{3}{*}{ Other defects } & 72 & 11 & GMP deficiencies and deviation from preapproved specifications & 48 \\
\hline & & & Inappropriate shipment & 14 \\
\hline & & & Dissolution/disintegration failure & 10 \\
\hline Total & 649 & 100 & & 649 \\
\hline
\end{tabular}


Table 2 Contaminated medicines subjected to urgent recalls (Health Product Recall type I)

\begin{tabular}{|c|c|c|}
\hline Medications (number of incidents) & Formulation & Defect description \\
\hline $\begin{array}{l}\text { Marcaine (2), acyclovir (1), nitroglycerin (1), } \\
\text { magnesium sulfate (1), dexamethasone sodium } \\
\text { (1), vistide (1) and carboplatin (1) }\end{array}$ & $\begin{array}{l}\text { Solution for } \\
\text { injection }\end{array}$ & $\begin{array}{l}\text { Visible particulates were identified in the formulation } \\
\text { (such as white, metallic or glass particles) }\end{array}$ \\
\hline Propofol (4) and fat emulsion (1) & $\begin{array}{l}\text { Emulsion for } \\
\text { injection }\end{array}$ & \\
\hline $\begin{array}{l}\text { Extraneal (1), ciprofloxacin (1), carmustine (1), } \\
\text { technetium Tc } 99 \mathrm{~m} \text { (1) and liposomal amphotericin } \\
\text { B (1) }\end{array}$ & $\begin{array}{l}\text { Solution for } \\
\text { injection }\end{array}$ & $\begin{array}{l}\text { Microbial contamination (bacterial, fungal or viral } \\
\text { contamination) }\end{array}$ \\
\hline Docusate sodium (1) & Capsules & \\
\hline Sucrose (1) & Oral liquid & \\
\hline Benzalkonium chloride (1) & Topical liquid & \\
\hline Sodium chloride (1) and dextrose (1) & $\begin{array}{l}\text { Solution for } \\
\text { injection }\end{array}$ & $\begin{array}{l}\text { Integrity of the foil seal is compromised leading to } \\
\text { potential contamination of the vial adapter }\end{array}$ \\
\hline $\begin{array}{l}\text { Dianeal (1), DTE technetium Tc 99m (1), } \\
\text { electrolyte infusion (1) and dextrose (1) }\end{array}$ & $\begin{array}{l}\text { Solution for } \\
\text { injection }\end{array}$ & Lack of sterility assurance at the time of manufacture \\
\hline Gen Teal Artificial Tears (1) & $\begin{array}{l}\text { Ophthalmic } \\
\text { Solution }\end{array}$ & \\
\hline Heparin sodium (3) & $\begin{array}{l}\text { Solution for } \\
\text { injection }\end{array}$ & Contamination with heparin-like contaminant \\
\hline Quetiapine (3) & Tablets & $\begin{array}{l}\text { Cross-contamination of trace amounts of clindamycin } \\
\text { in quetiapine active pharmaceutical ingredient during } \\
\text { the manufacturing process }\end{array}$ \\
\hline
\end{tabular}

marketing authorisation for 611 substandard medicines and distributors for 38 (table 4). No unlicensed manufacturers or distributors were involved. A comparison between those manufacturers and distributors in the number of substandard medicines reported under each defect type and the $\mathrm{p}$ values for these differences is presented in table 4. No significant differences were observed between manufacturers and distributors.

The top 20 manufacturers are listed in online supplementary table S4. It was noted that $50 \%$ or more of substandard medicines manufactured by Apotex Inc, Pfizer Canada Inc and Laboratoire Riva Inc had stability issues. Almost half of the substandard products from Baxter Co, Hospira Healthcare Co and GlaxoSmithKline Inc were contaminated. Products of Sandoz Canada Inc had a problem with the active ingredient; the concentration was either too high or too low. More than half of Novartis products, which are reported to be substandard, were recalled due to delivery concerns, such as failure of the child-resistant feature of the bottle cap or leaks in the infusion bags.

\section{Falsified medicines}

Four incidents of falsified medicines were identified in Canada's supply chain between 2010 and 2013. All these incidents involved two sexual enhancement medicines, Viagra (sildenafil) and Cialis (tadalafil).

In all cases of falsified medicines, PAs were issued to inform the public to contact their healthcare professionals if they had concerns about these falsified medicines. The public was also advised to verify that these products were assessed by Health Canada for safety by looking at the authorisation number printed on the label. These medicines were seized in the retail outlets in Canada, and no further information was given by Health Canada about the subsequent investigation or action taken by Health Canada.

\section{DISCUSSION}

This is the first review that discusses the issue of substandard and falsified medicines in Canada by evaluating the risk communication documents and drug recalls posted on Health Canada website. Our observations of defective medicines recalls over nine consecutive years, from 2005 to 2013, have shown that the recall of substandard medicines is an increasing trend. It is concerning that over half of the stability failures were related to instability of active ingredients or dissolution and disintegration failure. Both defects have the potential to affect the bioavailability of the active ingredients in the systemic circulation, and in turn, may lead to therapeutic failure.

\section{Substandard medicines}

The most frequent type of formulation reported to be substandard were tablets. Tablets have a slow onset of action and require less precaution in terms of sterility, than parenteral formulations. The extent of adverse consequences that can arise from failure to comply with manufacturing requirements, however, cannot be ignored. This was evident from the death of 120 patients in Pakistan due to contamination of isosorbide 
Table 3 Substandard medicines subjected to urgent recalls (Health Product Recall type I and Public Warning) with other defect types

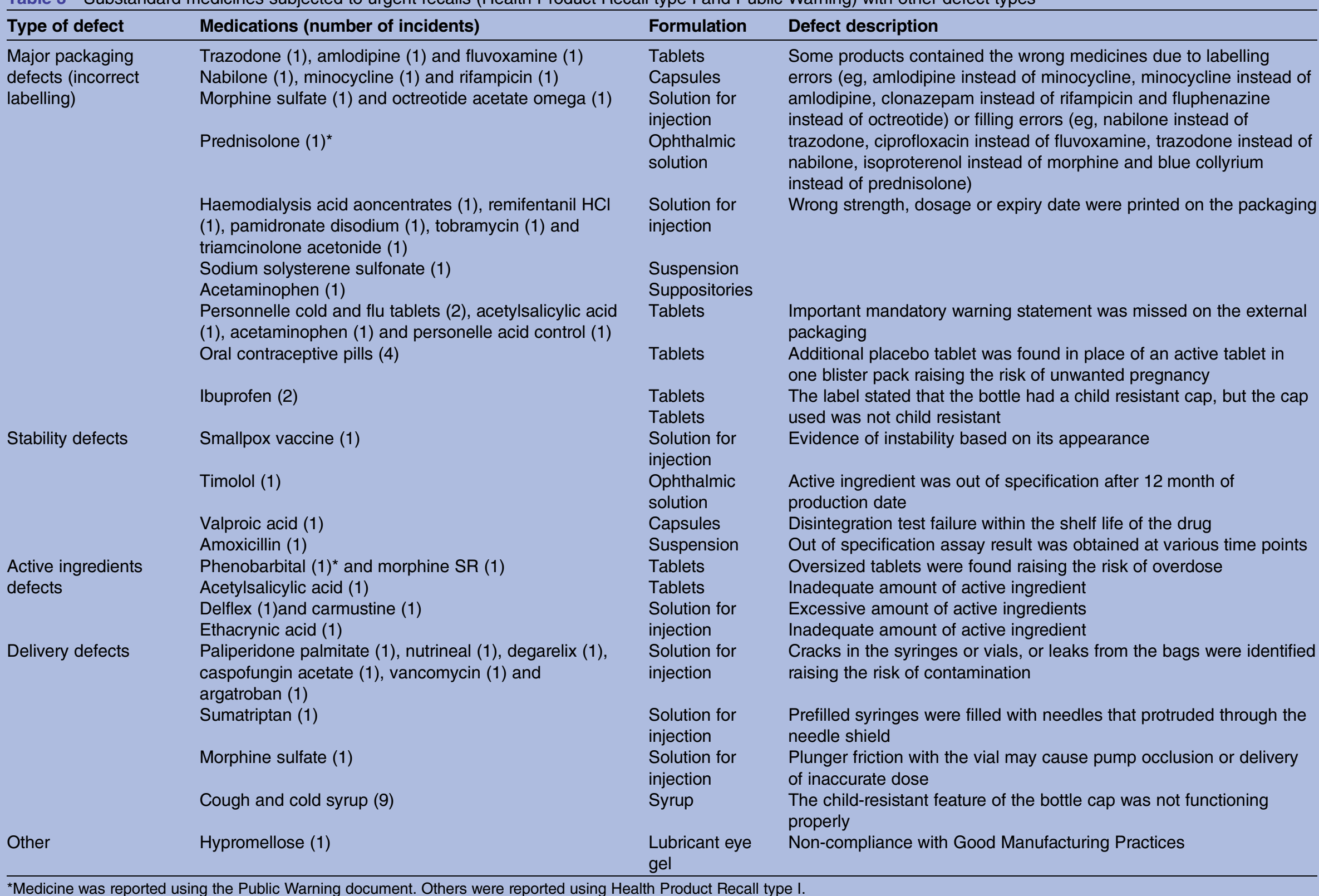

*Medicine was reported using the Public Warning document. Others were reported using Health Product Recall type I. 
Table 4 Substandard medicines categorised by type of marketing authorisation holders

\begin{tabular}{|c|c|c|c|}
\hline Type of quality defect & $\begin{array}{l}\text { Medicines marketed by } \\
\text { manufacturers }(n=122) \\
\text { Number of medicines (\%) }\end{array}$ & $\begin{array}{l}\text { Medicines marketed by } \\
\text { distributors }(n=26) \\
\text { Number of medicines (\%) }\end{array}$ & p Value \\
\hline Stability & $191(31)$ & $14(37)$ & 0.476 \\
\hline Contamination & $134(22)$ & $5(13)$ & 0.228 \\
\hline Minor packaging & $69(11)$ & $2(5)$ & 0.417 \\
\hline Major packaging & $60(10)$ & $5(13)$ & 0.573 \\
\hline Active ingredient & $59(10)$ & $3(8)$ & 1.000 \\
\hline Delivery & $34(5)$ & $1(3)$ & 0.714 \\
\hline Others & $64(11)$ & $8(21)$ & 0.058 \\
\hline Total & $611(100)$ & $38(100)$ & \\
\hline
\end{tabular}

${ }^{*} \mathrm{~A}$ significant difference was defined at a $p$ value $<0.05$.

mononitrate tablets with large doses of an antimalarial drug. ${ }^{16}$ Another of the most pronounced examples is the phenobarbital and morphine tablet recalls in Canada. Oversized tablets (ie, tablets that exceed the weight requirement) were found in both drugs, raising the risk of the patients taking as much as double the strength stated on the bottle (table 3). The Institute for Safe Medication Practices (ISMP), a non-profit organisation, stated that the US manufacturer (KV Pharmaceutical) received abnormally high reports of serious adverse events concerning overdose of these recalled tablets. ${ }^{17}$ However, owing to the lack of sufficient details, it was impossible to link the overdose events specifically to the substandard tablets. The adverse events relating to this defect have not been documented by Health Canada.

It was uncertain whether the rise of substandard medicines incidents were related to improved detection by Health Canada or due to an increase of substandard medicine production by manufacturers. The rate of increased incidence of substandard medicines could be associated with the implementation of improved detection policies and regulations by Health Canada. Introduction of Good Manufacturing Practices (GMP) inspection policy for Canadian drug establishments may be one of the explanations. ${ }^{18}$ Since 1996, there have been numerous changes in GMP guidelines and international agreements. These led Health Canada to update its policy on GMP inspection in January 2008 as a response to harmonise its GMP compliance programme with drug regulatory authorities in other countries. ${ }^{18}$ Subsequently, there has been a steady increase of incidents of substandard medicines from 2008 to 2013 (figure 2). Similarly, it has been highlighted that most of the FDA recalls were related to FDA inspectors' visits in the USA. ${ }^{19}$

The GMP policy illustrates the procedures Health Canada follows to ensure that all drug establishments comply with GMP guidelines. This is conducted via inspections with varying cycles according to a risk-based approach to assess complaints about medicines, and a ranking scale of priority. ${ }^{18}$ This assessment is to ensure that these complaints are dealt with in a timely manner. The performance of Health Canada in using the risk- based approach, however, was criticised in the 2011 report of the Auditor General of Canada. ${ }^{20}$ Based on a representative sample (50) of the files that Health Canada received in 2009 and 2010 concerning drug-related complaints, only 27 were dealt with according to the established risk-based standard operating procedures for prioritising reported complaints. The report concluded that Health Canada did not consistently apply its risk-based approach and therefore some of these complaints might not be processed in a timely manner proportional to their expected risk. ${ }^{20}$ Therefore, the possibility that the increase in substandard medicines was a result of poor manufacturing practices cannot be excluded.

\section{Manufacturing errors and investigation of the root cause}

It is the responsibility of the manufacturers and marketing authorisation holders to recall their substandard products after consultation with Health Canada. The majority of these recalls were issued by the manufacturers or marketing authorisation holders using the Health Product Recall type I, II and III, which accounted for $95 \%$ of the total substandard medicines reported. Stability issues were mainly identified by the manufacturers during ongoing stability testing. However, it is unknown whether these defects were identified by internal auditing systems of the manufacturers, by intervention of the Health Canada inspection team or by reports from healthcare professionals.

Analysing pharmaceutical product recalls can be of great importance to identify the root causes of recalled medicines. The prompting of a drug recall can be regarded as a disastrous failure of the manufacturer's quality plan. Even with stringent quality measures, errors can occur. ${ }^{21} 22$ Thus, it is very important to identify the root cause of the defects to avoid similar episodes in the future. The root cause for a defect is required to be submitted to Health Canada, as soon as it is identified, along with other information relating to the quantity and depth of the distribution of the affected medicine. It is the responsibility of Health Canada to monitor the overall procedure and assess the root cause for this problem and, if required, to conduct an inspection to 
verify that a corrective action is implemented. ${ }^{23}{ }^{24}$ It has been highlighted in this review that stability failure and contamination issues were the defect types being reported most frequently. These issues affected several manufacturers on more than one occasion (see online supplementary table S4). This highlights the need for root cause investigations and appropriate measures to be implemented by manufacturers as well as effective monitoring by Health Canada.

\section{Falsified medicines}

Only four incidents of falsified medicines were reported by Health Canada. The detection is extremely low compared with substandard medicine. Health Canada has robust GMP inspections that cover all drug establishments including manufacturers, distributors and wholesalers. The reporting system of Health Canada is concerned with falsified medicines detected within the scope of GMP inspections. ${ }^{18}$ Some falsified medicines may be intercepted and seized by enforcement bodies on their way to target destinations, but not necessarily intended for the Canadian market. This may explain the low detection rate by Health Canada.

\section{Comparison with the UK}

Despite the fact that Canada and the UK represent 2\% (for each) of the global pharmaceutical market volume, they are two of the top markets by value of marketed medicines. Canada and the UK hold equal global pharmaceutical market share values of US\$21 877 and US\$21 635 billion, respectively. ${ }^{25}$ They also use similar approaches in dealing with substandard medicines based on the expected risk. In the UK, the drug regulator uses four classes of drug alerts to communicate the risk of substandard medicines to healthcare professionals. ${ }^{6}$ A request to recall the affected batches is issued with the first three classes (class 1-3 drug alerts), comparable to the Health Product Recall type I, II and III issued by Health Canada. A class 4 drug alert is issued by the UK drug regulator when a drug recall is not required, but caution is needed to deal with a substandard medicine. This type of communication is similar to the PA, HPC-NtoH and HPC-DHCPL used by Health Canada. A class 1 drug recall (issued in the UK), and both the Health Product Recall type I and PW (issued in Canada) are considered to be urgent communications. The rest of the documents in both countries are deemed as semiurgent communications. ${ }^{6} 14$

Out of the 280 substandard medicines found in the UK, $17(6 \%)$ were subject to urgent communication. ${ }^{7}$ The corresponding number in Canada was 89 (14\%) out of 649. Overall, a larger number of substandard medicines were found in the Canadian supply chain (649 medicines) than in the UK (280 medicines) ${ }^{7}$ It is also important to mention that the UK study was conducted over a longer period (ie, 11 years) than the one on Canada (ie, 9 years). Therefore, the difference in the number of substandard medicines may be even larger than it appears. The major contributor to this difference in our data was the number of medicines recalled due to stability problems (figure 3 ), which were responsible for $50 \%$ of the difference. The differences in stability issues between Canada and the UK require further investigation.

\section{Limitations}

This study encountered some limitations. The expected adverse events associated with the use of substandard medicines were not reported by Health Canada or the manufacturers. Moreover, the adverse reaction database does not state the batch numbers of medicines reported with the complaint. Therefore, we could not compare the expected risk associated with the recalled batches of substandard medicines with the adverse drug reaction database. Thus, the clinical significance of the problem is unknown.
Figure 3 Comparison between Canada and the UK in the types of substandard medicines.

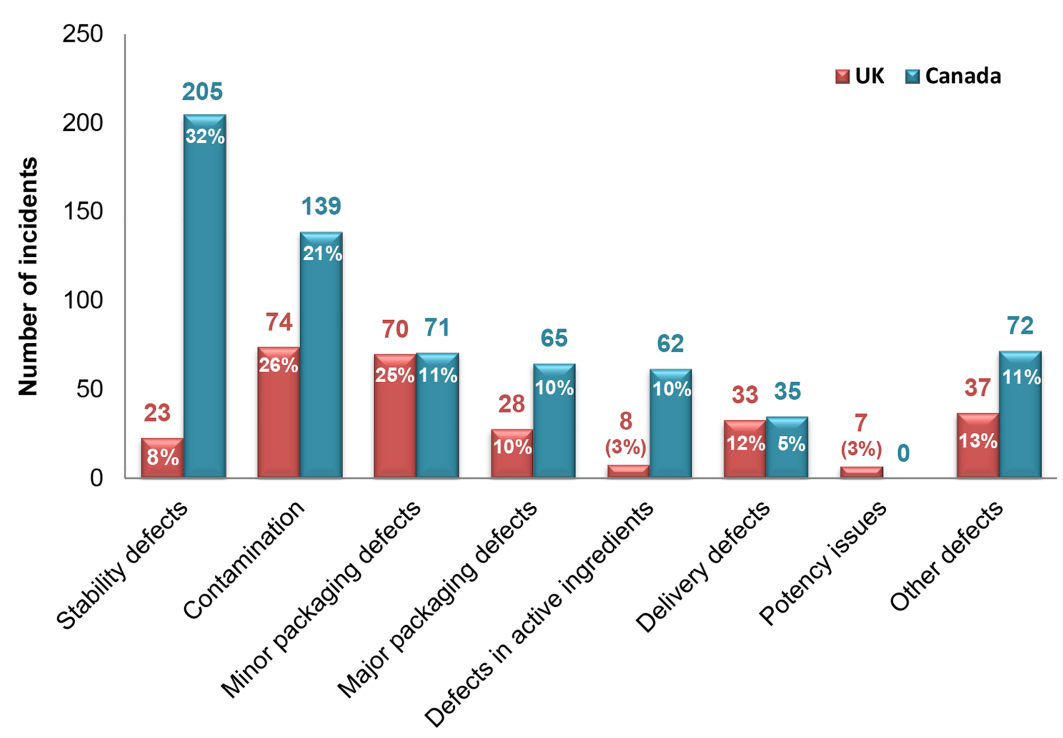




\section{CONCLUSION}

Substandard medicines are a problem in Canada and have resulted in an increasing number of recalled medicines. Most of the failures were related to stability issues, raising the need to investigate the root causes and for stringent preventative measures to be implemented by manufacturers. Regular GMP inspections on manufacturing sites were highlighted in this review as some of the most important tools that can improve detection of substandard medicines.

Contributors TA and IC conceived the study design and planned the research. TA performed the database search, extracted the data and drafted the manuscript. HS double-checked the extracted data, and interpreted the results. IC and HS edited and reviewed the manuscript. All authors approved the final version of the manuscript.

Funding This research received no specific grant from any funding agency in the public, commercial or not-for-profit sectors.

Competing interests None.

Provenance and peer review Not commissioned; externally peer reviewed.

Data sharing statement No additional data are available.

Open Access This is an Open Access article distributed in accordance with the Creative Commons Attribution Non Commercial (CC BY-NC 4.0) license, which permits others to distribute, remix, adapt, build upon this work noncommercially, and license their derivative works on different terms, provided the original work is properly cited and the use is non-commercial. See: http:// creativecommons.org/licenses/by-nc/4.0/

\section{REFERENCES}

1. Bate $R$, Coticelli $P$, Tren $R$, et al. Antimalarial drug quality in the most severely malarious parts of Africa-a six country study. PLoS ONE 2008;3:e2132.

2. Caudron JM, Ford N, Henkens $\mathrm{M}$, et al. Substandard medicines in resource-poor settings: a problem that can no longer be ignored. Trop Med Int Health 2008;13:1062-72.

3. Almuzaini T, Choonara I, Sammons H. Substandard and counterfeit medicines: a systematic review of the literature. BMJ Open 2013;3: e002923.

4. Mackey TK, Liang BA. The global counterfeit drug trade: patient safety and public health risks. J Pharm Sci 2011;100:4571-9.

5. Bate $R$, Jensen $P$, Hess $K$, et al. Substandard and falsified anti-tuberculosis drugs: a preliminary field analysis. Int $J$ Tuberc Lung Dis 2013;17:308-11.

6. MHRA. A guide to defective medicinal products. http://www.mhra. gov.uk/home/groups/is-lic/documents/publication/con007572.pdf (accessed 25 Sep 2014).
7. Almuzaini T, Sammons H, Choonara I. Substandard and falsified medicines in the UK: a retrospective review of drug alerts (2001-2011). BMJ Open 2013;3:e002924.

8. Attaran A, Barry D, Basheer S, et al. How to achieve international action on falsified and substandard medicines. BMJ 2012;345:e7381.

9. Ninan B, Wertheimer A. Withdrawing drugs in the U.S. versus other countries. Innov Pharm 2012;3:1-12.

10. Lexchin J. New drugs and safety: what happened to new active substances approved in Canada between 1995 and 2010? Arch Intern Med 2012;172:1680-1.

11. FDA. Counterfeit Version of Avastin in U.S. Distribution (2012). http://www.fda.gov/drugs/drugsafety/ucm291960.htm (accessed 25 Sep 2014).

12. Davies E. More US citizens die from meningitis as scope of inquiry widens. BMJ 2012;345:e7095.

13. Health Canada. Drugs and Health Products. http://www.hc-sc.gc.ca/ dhp-mps/index-eng.php (accessed 25 Sep 2014).

14. Health Canada. Description of Current Risk Communication Documents for Marketed Health Products for Human UseGuidance Document. http://www.hc-sc.gc.ca/dhp-mps/pubs/medeff/ guide/2008-risk-risques_comm_guid-dir/index-eng.php (accessed 25 Sep 2014).

15. WHOCC. ATC Structure and principles. http://www.whocc.no/atc/ structure_and_principles/ (accessed 25 Sep 2014).

16. Arie S. Contaminated drugs are held responsible for 120 deaths in Pakistan. BMJ 2012;344:e951.

17. The Institute for Safe Medication Practices (ISMP). Serious adverse drug event reports increase $25 \%$ in 2008. http://www.ismp.org/ QuarterWatch/2008Q4.pdf (accessed 25 Sept 2014).

18. Health Canada. GMP Inspection Policy for Canadian Drug Establishments (POL-0011). http://www.hc-sc.gc.ca/dhp-mps/ compli-conform/gmp-bpf/pol/pol_0011_insp_drug_Itr-doc-eng.php (accessed 25 Sep 2014).

19. Dickinson J. Most recalls due to FDA inspection findings. Med Mark Media 2001;36:30.

20. Auditor General of Canada. 2011 Fall Report of the Auditor General of Canada. Chpter 4: Regulating Pharmaceutical Drugs-Health Canada. http://www.oag-bvg.gc.ca/internet/english/parl_oag_ 201111_04_e_35936.html\#hd4d (accessed 25 Sep 2014).

21. The Institute of Medicine (IOM). Countering the Problem of Falsified and Substandard Drugs report. 2013. http://www.iom.edu/Reports/ 2013/Countering-the-Problem-of-Falsified-and-Substandard-Drugs aspx (accessed 25 Sep 2014).

22. Food and Drug Administration (FDA). Guidance for industry: product recalls, including removals and corrections. Rockville, Maryland, 2003. http://www.fda.gov/Safety/Recalls/IndustryGuidance/ ucm129259.htm (accessed 27 Sep 2014)

23. Health Canada. Health Products and Food Branch InspectorateRecall Policy (POL-0016). 2006. http://www.hc-sc.gc.ca/dhp-mps/ compli-conform/info-prod/drugs-drogues/pol_0016_tc-tm-eng.php (accessed 25 Sep 2014)

24. Health Canada. Compliance and Enforcement Policy (POL-0001). 2005. http://www.hc-sc.gc.ca/dhp-mps/compli-conform/gmp-bpf/pol/ pol_1_tc-tm-eng.php (accessed 25 Sept 2014).

25. Association of the British Pharmaceutical Industry (ABPI). Global pharmaceutical industry and market. http://www.abpi.org.uk/ industry-info/knowledge-hub/global-industry/Pages/industry-market-. aspx (accessed 25 Sept 2014). 